\title{
ENTRE LIVES E PANDEMIA \\ um relato de percurso do projeto Sensíveis Perspectivas
}

BETWEEN LIVESTREAMS EVENTS AND PANDEMIC

an account of the journey of the Sensíveis Perspectivas project

\author{
Anamaria Sobral Costa \\ https://orcid.org/oooo-0oo1-9229-6723 \\ UFPE, atriz, Doutora em Comunicação \\ Eline Gomes de Araújo \\ (iD) https://orcid.org/oooo-0oo2-2276-3610 \\ UFPE, médica, Mestra em Dança \\ Taciano Valério Alves da Silva \\ (i) https://orcid.org/oooo-0002-3013-7425 \\ UFPE, cineasta, Doutor em Psicologia \\ Clínica
}

\author{
Andrew Pereira da Silva \\ (D) https://orcid.org/oooo-00o2-1919-4648 \\ UFPE, estudante de Medicina \\ Karlla Stephanie Silva \\ (iD) https://orcid.org/oooo-0002-6698-2014 \\ UFPE, estudante de Medicina \\ Pedro Érico de Souza \\ (D) https://orcid.org/00oo-0003-1207-6769 \\ UFPE, estudante de Medicina
}

\section{RESUMO}

Este relato descreve os caminhos do projeto de extensão Sensíveis Perspectivas, proposto pelo Laboratório de Sensibilidade (LabSensi), um laboratório conectado ao Núcleo de Ciências da Vida, da Faculdade de Medicina, do Centro Acadêmico do Agreste, da Universidade Federal de Pernambuco (UFPE). O projeto compreendeu a realização de sete lives, discutindo e debatendo uma crise sanitária em meio à pandemia de Covid-19, que envolveram profissionais de saúde e de diversas outras áreas do conhecimento, a fim de alcançar uma abordagem sistêmica do problema, que inclui a via do sensível e os itinerários estéticos, éticos e sociais como dimensões incontornáveis para um pensamento integral em saúde.

Palavras-Chave: Saber Sensível; Covid-19; Saúde; Ética; Estética.

\section{ABSTRACT}

This report describes the paths of the extension project Sensiveis Perspectivas, proposed by the Sensitivity Laboratory (LabSensi), a laboratory connected to the Life Sciences Department of the Faculty of Medicine of the Agreste Academic Center of UfPE. The project comprised the realization of seven livestream events in order to discuss and debate the health crisis caused by Covid-19 pandemic. The project involved professionals from health care 
and from several other areas to achieve a systemic approach to the problem, which includes the path of the sensitive and the aesthetic, ethical and social itineraries as unavoidable dimensions toward an integral health thinking.

Keywords: Sensitive Knowledge; Covid-19; Health; Ethics; Aesthetics.

\section{APRESENTAÇÃO}

Do desafio de continuar o trabalho de potencialização dos aspectos éticos e humanitários, e ligados às artes e à sensibilidade, na formação em saúde em meio à pandemia de Covid-19, surge o projeto Sensíveis Perspectivas. Produzido como projeto de extensão pelo Laboratório de Sensibilidades (LabSensi) do Núcleo de Ciências da Vida (NCS) do Centro Acadêmico do Agreste (CAA), da Universidade Federal de Pernambuco (UFPE), em parceria com o Núcleo de Cartografias da Subjetividade, da Universidade de Pernambuco (Nucas/UPE), o Sensíveis Perspectivas realizou sete lives, sete programas feitos ao vivo pelo canal do Nucas no Youtube. Nessas lives, realizadas entre os meses de maio e junho de 2020, profissionais de diversas áreas debateram questões emergenciais voltadas para o fortalecimento de uma saúde pública sistêmica e integral, promovendo discussões para além do campo biomédico.

As lives, intituladas "As existências mínimas: por uma ética da pluralidade na saúde" (4 de maio), "A sociologia do vírus, ou quando o biológico é social" (11 de maio), "Entre o medo e a morte: sensações em meio à pandemia” (18 de maio), “Tramas performáticas como modos de existência” (25 de maio), “Corpos em 'risco': por uma ética do cuidado" (10 de junho), "Pandemia, arte e subversão" (8 de junho) e "Desafios do sus para o enfrentamento da pandemia: da política à produção do cuidado em saúde" (15 de junho), atingiram um total de 2.479 visualizações no canal do Nucas até o dia 23 de julho de 2020. No entanto, embora esse aspecto numérico seja frequentemente valorizado na avaliação do alcance desses canais de comunicação, não é o elemento quantitativo que pretendemos abordar neste relato.

O objetivo deste texto é relatar o percurso do projeto, enfatizando os questionamentos suscitados e os diálogos com estudantes e profissionais de saúde e de outras áreas, bem como a nossa busca por formas possíveis de convívio, segundo as recomendações 
de distanciamento social vigentes na maior crise sanitária dos últimos 100 anos.

A seguir, trazemos algumas considerações que sintetizam o modo como produzimos e refletimos sobre cada uma dessas lives e sobre os disparadores teóricos relevantes para pensar as questões práticas, mas também subjetivas, a respeito do papel da/do profissional da saúde e da universidade pública, no presente contexto de crise.

\section{DIANTE DO CAOS, SÓ LIVES}

Quando as "trombetas" do caos pandêmico impuseram a necessidade de uma nova configuração existencial, o LabSensi do CAA/ UFPE avaliou a possibilidade de produzir uma inserção a partir dos marcadores que o acompanham ao longo do tempo, ou seja: a busca por trabalhar um saber sensível, que não opõe sensação e emoção à razão; a criação de espaços para a reflexão e o cuidado de si, para uma maior compreensão e empatia no cuidado com o outro, e para uma perspectiva e uma prática da saúde como algo indissociável das questões sociais, ecológicas, psicológicas e subjetivas que envolvem invariavelmente o sujeito humano.

Seria necessária uma ação ética, que estivesse inscrita num nível micropolítico e também estético, já que entendemos a arte como uma dimensão inalienável de qualquer perspectiva integral do ser humano. Assim, as professoras Anamaria Sobral e Eline Gomes e o professor Taciano Valério se reuniram para pensar uma ação emergencial que viabilizasse uma forma de expressão sobre a pandemia, problematizando suas variáveis, numa via de mão dupla entre a academia e a sociedade. Pensamos que a melhor forma seria a extensão universitária.

Como sabemos, a extensão universitária privilegia uma articulação da universidade com a comunidade, gerando um espaço de coparticipação. Logo, pensamos quais seriam as possíveis ressonâncias de um projeto como esse nos territórios existenciais das pessoas, no trabalho, na saúde e no cotidiano. Nesse momento, o LabSensi foi convidado pelo Nucas/Upe (campus Garanhuns) a participar de uma live: "O sensível em tempos de coronavírus".

Dessa experiência, que consideramos uma espécie de projeto piloto, surgiu a ideia de criar uma parceria com a UPE para a realização do projeto, que compreenderia inicialmente seis lives, que abordariam temas pertinentes a uma reflexão sobre a saúde pública no Brasil atual: a solidão de doentes e de profissionais de saúde, a sensibilidade que aflora ante a proximidade da morte, o 
medo e a incerteza diante do novo coronavírus, a crise política que dividiu governo federal, estados e municípios - e que vem dificultando o enfrentamento da crise -, o negacionismo ante a doença, as interfaces entre arte e saúde, o lugar e o não lugar da arte na sociedade, e as relações de todo esse contexto com a crise humanitária no campo da medicina.

Convidamos três estudantes do curso de medicina da UFPE (campus Caruaru), cuja participação no Laboratório de Sensibilidades se destacou tanto pela frequência quanto por sua dedicação. Assim, Karlla Stephanie, Andrew Pereira da Silva e Pedro Érico passaram a integrar a equipe. Paralelamente, a pandemia ganhava contornos cada vez mais urgentes, ou seja, tínhamos o descortinamento sanitário do fenômeno, de modo que o Sensíveis Perspectivas se desdobrou, a despeito do caos, por meio de lives.

\section{ENTRE LIVES E A PANDEMIA}

Discutimos quais debatedoras e debatedores iriam colaborar com o projeto; eles deveriam abranger tanto profissionais de saúde quanto pessoas que pensassem a pandemia a partir de aspectos sociais, éticos e estéticos, o que seria fundamental para que se concretizasse uma abordagem sistêmica, na qual os aspectos da vida não podem ser segmentados, sob pena de excluirmos pontos fundamentais à compreensão do problema.

Partindo de um argumento escrito, para nos dar clareza do panorama epistêmico de cada discussão, o Sensíveis Perspectivas entrou na rede, na mídia social, configurando-se como espaço de diálogo. Seguem os relatos desses encontros.

\section{AS EXISTÊNCIAS MÍNIMAS: POR UMA ÉTICA}

DA PLURALIDADE NA SAÚDE

O “existir mínimo”, aludindo às ideias do filósofo David Lapoujade, refere-se às pessoas e comunidades que emergem enquanto maioria, mas que têm suas existências vistas como periféricas, marginalizadas, invisíveis, anômalas. Trata-se de uma maioria silenciada, pois, supostamente, não é contemplada pelo status quo. Como exemplos dessas existências, temos: o indígena, o negro, as comunidades LGBTQIA+, os quilombolas, os pobres, os idosos, e todos aqueles que, em sua multiplicidade de sentimentos, gestos e práticas, destoam dos modos hegemônicos (LAPOUJADE, 2017). Numa lógica cada vez mais privatizada da saúde, voltamo-nos para essas “existências mínimas”, em prol de uma prática em saúde que exerça uma ética da pluralidade. 


\section{(6) \\ Numa lógica cada vez mais privatizada da saúde, voltamo-nos para essas 'existências mínimas', em prol de uma prática em saúde que exerça uma ética da pluralidade}

O debate se inicia com a filósofa e concluinte do Curso de Medicina da UfPE Duda Spencer. Ela discute o conceito de "existências mínimas", rememorando a recente fala do ambientalista Ailton Krenak, referente ao sequestro de identidade da maioria das populações que saem dos campos e das florestas para viver nas periferias dos centros urbanos; e nos lembra da imensa dívida ética e social que a sociedade brasileira tem com essas existências (KRENAK apud SPENCER, 2020). Em seguida, cita o aumento do número de garimpeiros invadindo os territórios indígenas e a quantidade de indígenas acometidos pela malária, em pleno período de pandemia, refletindo sobre as ameaças enfrentadas pelas minorias, e sobre o quanto elas estão mais vulneráveis que os demais estratos da sociedade. De acordo com Spencer, para haver uma ética da pluralidade na saúde, as/os representantes dessas populações devem ser ouvidas/os por responsáveis pelo sistema de saúde, sobre quais são as suas necessidades e construindo em conjunto um processo de saúde que seja ético e participativo, e não colonizador e necropolítico.

Prosseguindo com a discussão, o professor da Universidade Federal de Alagoas e Doutor em Psicologia Saulo Luders ressalta a importância do cuidado da vida para além do cuidado da saúde, uma vez que esse conceito é bem mais amplo e se associa às existências em suas relações com a terra, com a natureza, com o ar que se respira; ele discorre sobre sua experiência com os povos indígenas, fazendo uma conexão com o texto do filósofo Achille Mbembe (2020): O direito universal à respiração. Em seguida, Luders fala da dificuldade da academia de incluir um debate consistente sobre 
os povos tradicionais, partindo do pressuposto de que tais discussões são específicas e periféricas. Luders ressalta a importância de integrar ao debate acadêmico os conhecimentos e culturas desses povos, e cita o sociólogo Boaventura de Sousa Santos (2007) (e sua posição a respeito de a sociedade ser composta por um sistema de distinções visíveis e invisíveis, que dividem a realidade social em dois universos ontologicamente diferentes). Ele também se refere à filósofa boliviana Silvia Rivera Cusicanqui e ao seu conceito de "Ch'ixi” (conviver com a alteridade) (CUSICANQui, 2012). Luders afirma que não acredita que, após a pandemia, a sociedade se tornará uma coletividade perfeita, mas que aprofundará ainda mais o estilo de vida capitalista e abissal; contudo, ele percebe que a capacidade de sonhar das pessoas está sendo construída, como é preconizado pelo líder indígena Ailton Krenak (2019).

O terceiro participante é o Doutor em Bioética, professor e Diretor do NCV/CAA/UfPE Saulo Feitosa. Retomando a definição de "existências mínimas", ele enfatiza que todas as existências são máximas e plenas, como é preconizado pelas filosofias indígenas e andinas; porém, segundo os filósofos que trabalharam o conceito, essas existências ganham nuances distintas. Citando Lapoujade:

\footnotetext{
Penso em uma criança que dispôs diversos objetos, grandes e pequenos, cuidadosamente, longamente, de uma maneira que ela achou bonita e ornamental, sobre a mesa de sua mãe, para "agradá-la". A mãe chega. Tranquila, distraída, pega um desses objetos, do qual ela vai precisar, recoloca um outro no seu lugar de sempre, e desfaz tudo. E quando as explicações desesperadas que acompanham os soluços contidos da criança the revelam a extensão do seu pouco caso, ela exclama desolada: "Ah, meu amor, eu não vi que era alguma coisa!". Eu não vi... O que é que ela não vê? Que "alguma coisa" é essa que a mãe não vê? [...]. Ela vê os objetos, pois mexe neles e os arruma, o que ela não vê é o modo de existência deles sob o ponto de vista da criança, a arquitetura esboçada diante de seus olhos (LAPOUJADE apud FEITOSA, 2020)
}

Feitosa defende que só há como discutir as pluralidades éticas na saúde quando se reconhecem as diversas formas de existência. Daí a importância de se viver as sensibilidades nos cursos de saúde, para formar o olhar dos futuros profissionais de forma descolonizada, livre de preconceitos sobre as diversas minorias étnicas, e partindo de uma intermedicalidade (terapias que agem em conjunto com as crenças culturais e práticas terapêuticas dos diversos povos).

O debate suscitou várias perguntas e intervenções no chat, auxiliando-nos a polir nossas lentes como docentes e comunidade 
acadêmica, de modo a fazer enxergar os saberes frequentemente invisibilizados dessas "existências mínimas".

A SOCIOLOGIA DO VÍRUS, OU QUANDO O BIOLÓGICO É SOCIAL

No algoritmo da doença, as condições de alimentação, de moradia, os aspectos comportamentais e psicológicos ampliam de modo mais complexo os chamados grupos de risco. A pandemia de Covid-19, na qual as principais recomendações são o distanciamento social e a higienização constante das mãos, dos alimentos e dos objetos, torna ainda mais dramáticas as vidas nas periferias dos centros urbanos. E se o sistema de saúde está em iminente colapso por falta de vagas, há indícios de que o acesso a ele é ainda mais difícil no interior.

O professor da Universidade Federal do Agreste de Pernambuco e Doutor em Pós- Colonialismos e Cidadania Global Caetano de Carli enfatiza a importância de pensar como a crise atual agrava problemas que já existiam, e defende que o enfrentamento da pandemia passa por uma perspectiva social, e não estritamente científica. De Carli lembra que estamos lidando com os efeitos de uma crise econômica deflagrada em 2009 e de uma agenda neoliberal de cortes bruscos nos orçamentos dos estados, do Sistema Único de Saúde (sus) e de um sucateamento dos serviços públicos de um modo geral. Além disso, a ascensão de uma nova direita com características semelhantes às do "fascismo clássico" - representada por Donald Trump (EUA), Jair Bolsonaro (Brasil), Salvini (Itália)

\section{4}

estamos lidando com 
e Boris Johnson (Inglaterra) -, que minimizou e, em alguns casos (como no Brasil), até mesmo negou a validade dos argumentos da ciência sobre o vírus, torna a crise ainda mais difícil.

De Carli aponta a gravidade do avanço descontrolado do agronegócio e do uso de agrotóxicos, adubos químicos e do maquinário agrícola, que gera desemprego no campo e adensamento das populações urbanas, como aspecto complicador da atual crise sanitária. Tal fato é complementado pelos hábitos da população de consumir alimentos ultraprocessados, que passam a ser estocados dentro de casa.

As dificuldades de saneamento básico, a vulnerabilidade dos pequenos agricultores e os hábitos de consumo alimentar são alguns dos aspectos a serem levados em conta para pensarmos que tipo de sociedade nós queremos durante e após a crise da Covid-19.

Artur Perrusi, psiquiatra, Doutor em Sociologia e professor da Graduação e da Pós-Graduação em Sociologia na UFPE, inicia sua fala indagando quais seriam as determinações sociais da doença e problematizando as dicotomias entre o que é interno e o que é externo, bem como as separações entre biológico, psicológico e social. Ele argumenta que tais separações devem se limitar, no máximo, ao campo analítico, já que, do "ponto de vista realístico", tudo aparenta estar misturado. Exemplificando essa mescla, ele cita os transtornos de ansiedade (nos quais uma determinação social relacionada a vínculos com determinadas pessoas pode condicionar ansiedade e angústia) e a síndrome do pânico, que estaria relacionada ao surgimento de novos tipos de relações afetivas e sociais no mundo contemporâneo.

Perrusi lembra que a teoria de alguns autores permite enxergar o vírus como actante (LATOUR, 2000), chamando a atenção para o fato de que vivenciamos relações sociais produzidas por algo não humano. $\mathrm{O}$ vírus encontraria no Brasil um modelo de mercado que separa economia e vida; e cita a política do ministro Paulo Guedes como uma necroeconomia, na qual não há compromisso moral e ético com as pessoas.

Dissertando sobre o que seria "a ideologia do vírus", e sobre uma "luta pela verdade do vírus", Perrusi destaca formulações que circularam a respeito da pandemia: "o vírus é uma gripezinha", "o vírus é uma conspiração chinesa”, “o vírus é uma praga divina”. Tais perspectivas escancaram discursos não só autoritários, mas que teriam raízes no passado, seja no integralismo brasileiro, seja no fascismo, que é uma mistura de darwinismo social e eugenia. Quando Bolsonaro afirma que 70\% dos brasileiros serão 
contaminados pelo novo coronavírus, ele possui um raciocínio designado como capacitismo, no sentido prosaico: "quem sobreviver, ótimo; quem morrer, paciência; era fraco, e daí?". Trata-se de um discurso negacionista, um discurso anticientífico, mas que revela uma indiferença à vulnerabilidade. Assim, a sociologia do vírus pode ser vista como uma sociologia moral. Não causa surpresa que a discussão se torne cada vez mais politizada em relação à pandemia. Ele conclui afirmando que a sociologia do vírus escancara as estratificações sociais de raça, de gênero e de classe, inerentes à sociedade brasileira.

A Doutora em Antropologia e professora da Pós-Graduação em Antropologia da UFPE e do Mestrado em Culturas Africanas da Diáspora e dos Povos Indígenas da UPE Vânia Fialho propõe olharmos para como a pandemia vem afetando as comunidades tradicionais (incluindo indígenas e quilombolas), e enfatiza a importância de entendermos que as doenças não se constituem apenas por fatores "biológicos". Fialho alerta para o fato de que, no contexto da pandemia, estamos escolhendo quem vai morrer e quem vai viver; e de que, antes mesmo disso, temos selecionado quem tem e quem não tem sua existência reconhecida. Trabalhar com indígenas e quilombolas implica reconhecer a existência de populações que muitas vezes foram tratadas como não humanas, segundo uma perspectiva de "evolução" (darwinismo social) que desqualificava a sua participação na "comunhão nacional". Tal problemática se intensifica no contexto da pandemia, pois, se para esses povos a questão do reconhecimento territorial, da regularização fundiária e do reconhecimento das terras em que vivem sempre foi fundamental, temos hoje uma transposição desse campo de disputa para o campo da saúde. Determinadas ações desses segmentos, como o bloqueio de entrada e saída e a definição de fronteiras de seus territórios se tornam questões de garantia de sua saúde.

A ausência de uma política indigenista consistente torna ainda mais crítica a situação dos povos indígenas durante a pandemia, uma vez que, segundo Fialho, só podem acessar o subsistema de saúde indígena os povos que são considerados aldeados, ou seja, aqueles que vivem em um território que é reconhecido pelo Estado brasileiro. Aqueles que vivem fora desses espaços reconhecidos não podem acessar a assistência à saúde, não sendo contabilizados nesse processo. Assim, nega-se a existência daqueles indígenas que vivem nas periferias, nos centros urbanos e até mesmo nas áreas rurais. 


\section{(4) \\ Como o corpo por trás desses paramentos [os EPIs] se organiza no cotidiano da linha de frente? Como ele se percebe? Como lida com o risco e a morte presentes?}

Fialho finaliza lembrando que, ao mesmo tempo que precisamos observar as regras de distanciamento, há "investidas vorazes sobre o desmatamento, a exploração mineral, a grilagem, que aumentaram nesse momento em que os segmentos e os povos são confinados". Ela cita a "ideologia da decadência", conceito de Alfredo Wagner Berno de Almeida (2008), segundo o qual populações pobres, consideradas fracas e decadentes, estariam fadadas ao extermínio. Para combater a naturalização dessa ideologia seria importante pensar na epidemiologia do vírus e na sociologia moral, como dito por Perrusi, para não naturalizar decisões políticas que autorizam a ocorrência de outros genocídios.

ENTRE O MEDO E A MORTE: SENSAÇÕES EM MEIO À PANDEMIA

As relações de cuidado em saúde implicam a ponderação entre o risco biológico e a assistência. Com os equipamentos de proteção individual (EPIs), mal conseguimos enxergar quem está por trás da máscara e de todos os paramentos. Esses corpos cheios de EPIs estão privados de seus próprios cuidados cotidianos, já que os EPIs não podem ser desperdiçados e estão escassos, com seu uso regrado. Como o corpo por trás desses paramentos se organiza no cotidiano da linha de frente? Como ele se percebe? Como lida com o risco e a morte presentes? Há ainda os corpos que morrem sem sequer conseguir a assistência à saúde, seja pela superlotação dos hospitais, pela ausência de leitos de UTI, ou mesmo porque fizeram o isolamento domiciliar e não foi percebido o momento oportuno de procurar assistência, a fim de evitar uma morte solitária/desassistida. 
Diogivânia Maria da Silva, psicóloga, Doutora em Psicologia (UFPE), docente e supervisora do Centro Universitário do Vale do Ipojuca (Unifavip), discorre sobre como ela tem ouvido, de dentro de casa, o mal-estar coletivo. Ela diz que os tempos atuais nos lembram tempos de guerra, aludindo ao vírus como um bombardeiro e citando Judith Butler, para quem o que caracteriza a vida é a nossa capacidade de duelar por ela. Ou seja, "se você não consegue derramar uma lágrima por aquela vida, é porque aquela vida não está passível de luto, de duelo" (BUTLER, 2020). Ela cita a obra Necropolítica, de Achille Mbembe (2018), segundo o qual o Estado produz as vidas que devem permanecer vivas e as que devem morrer. $\mathrm{O}$ autor afirma ainda que o contemporâneo é extremamente violento, e que essa violência é a metástase do corpo social (MBЕмBE, 2018a). A pandemia potencializa e escancara o que já agonizava no corpo social, produzindo uma intensificação da desigualdade social e de outras injustiças. Esse fato, naturalmente, acionaria medo, pavor e terror nos nossos corpos. Silva lembra do memorial on-line dedicado às vítimas do coronavírus no Brasil, citando o cantor Chico César, que compôs uma canção para duelar por essas vidas: "se números frios não tocam a gente, espero que nomes consigam tocar".

O segundo convidado, Pedro Carvalho Diniz, médico, defensor do sus, membro da Rede Nacional de Médicas e Médicos Populares (RNMMP) e plantonista da UTI do Hospital Universitário da Universidade Federal do Vale do São Francisco, em Petrolina, Pernambuco, traz a perspectiva de quem trabalha na linha de frente no combate à doença, dizendo que a sensação de guerra se faz presente, seja pelos meios de comunicação, pela mobilização mundial, pelo clima gerado com a paramentação (ele diz que parece um cavaleiro medieval ao entrar na UTI). A Covid-19 vem atrelada a um período de liderança ausente (ou de uma contraliderança), desmandos e ideologias da anticiência, que agravam o medo e afetam o nosso humor no dia a dia. A pandemia viria para mudar a forma como tratamos da morte, tornando o medo algo coletivizado. Diniz afirma ter visto um motoqueiro tentando colocar o capacete por cima da máscara N95, em uma rua vazia, refletindo sobre a cena não só pelo lado cômico, mas também pela perspectiva do medo: “o mundo tá mascarado, os corpos tão mascarados e o medo está desmascarado... o medo tem mais rosto que as pessoas". Ele compara o medo das pessoas em situação de vulnerabilidade social, o medo de morrer sem um leito de UTI, ao medo de ser alvejado pela polícia. Finaliza afirmando que esse quadro vai acirrar 
as diferenças sociais, e que, se não tivermos ações sociais voltadas para essa população (papel primordial do sus e da Atenção Básica), esta sofrerá ainda mais neste sistema colapsado em que vivemos.

Nirlyn Seijas é artista do corpo, docente, pesquisadora, mãe adotiva e feminista. É curadora e docente do bacharelado interdisciplinar em artes da UFBA, Mestra em Cultura e Sociedade (UFBA), doutoranda no mesmo programa. Ela fala que um dos trabalhos da arte é imaginar narrativas possíveis, não para negar o que acontece, mas, sim, para torná-lo mais passível de se viver, e até mesmo, assim, a própria morte. A pandemia acontece num tecido social já fragilizado. Cada um de nós deve achar o sentido em tudo que está acontecendo, para atravessar o momento. Ela lembra das pessoas que colocam a sua "carne" em jogo, como aquelas que trabalham com delivery, nos mercados e nas atividades essenciais como um todo, para garantir que o corpo social continue funcionando. Seijas argumenta que a criatividade, a possibilidade de reinventar o medo e de se reafirmar dentro do sistema da vida fazem da arte algo de grande ajuda nesse momento. Questionando o que seria de nós sem arte (música, poesia etc.), ela narra sua experiência num treino de corpo, aberto ao público (virtualmente), e o quanto isso virou um pilar para as pessoas que dele participam, constituindo um lugar em que, por meio dos gestos corporais, sentimentos são ressignificados e outras fortalezas são construídas a partir da fragilidade do momento.

\section{TRAMAS PERFORMÁTICAS COMO MODOS DE EXISTÊNCIA}

Em vez de abordar as questões da pandemia a partir de uma discussão centrada na palavra, esse encontro se pautou na arte e na performance como formas de buscar alternativas de respiro, outras formas de luta.

Heloísa Germany, artista virtual, Especialista em Saúde Mental e Mestra em Saúde Coletiva (UFRGS), apresenta uma proposta de videoarte, com intervenção ao vivo, na qual ela contorna, recontorna, risca e transforma seu corpo, que passa a compor uma espécie de entidade outra. Uma entidade híbrida entre a representação e o performar-se.

Odécio Antônio, palhaço, ator, realizador audiovisual, traz um número com texto de sua autoria, glosando com irreverência e mordacidade o contexto político atual.

Já a cantora, compositora, poeta, e que também se apresenta como mãe e "artista inquieta", Ana de Anis, canta algumas coisas que lhe são significativas, e abre também outra janela de sentidos e sentires. 
Talvez seja essa a live mais difícil de descrever, ou de traduzir em palavras, porque se constitui da criação de movimentos e de rupturas diante dos debates e discussões costumeiramente associados à academia. As artistas e o artista parecem criar outros espaços, rasgar os mapas de nossos automatismos cotidianos, forjando suas realidades com a liberdade para cantar, poetizar, dançar, pular, brincar, rir, sujar, rasgar, pintar, apagar, monologizar, inquietando nossos processos de subjetivação e nos exigindo a criação de novas estratégias para sentir, pensar e existir. Da performance de Heloísa Germany surgiram o insight, o desejo e a ideia para a próxima live.

CORPOS EM RISCO: POR UMA ÉTICA DO CUIDADO

A experiência em sociedade marca nossos corpos de inúmeras maneiras. Há as marcas genéticas e étnicas, as sociais e culturais, as estéticas. No contexto da pandemia, dentro do campo biomédico, temos grupos de pessoas consideradas como pertencentes aos "grupos de risco": idosos, obesos e gestantes, além das que sofrem com hipertensão, diabetes, asma ou quaisquer outras condições patológicas que afetem o sistema imunológico. Diante desse contexto, nós nos perguntamos: quais as implicações científicas, humanitárias e mesmo estéticas de ser "marcado" como grupo de risco? Como podemos pensar uma ética e uma estética do cuidado que não reforce preconceitos já tão entranhados em nosso convívio social? Como trabalhar de modo não estigmatizante, considerando as pessoas em suas singularidades, e não como blocos de risco?
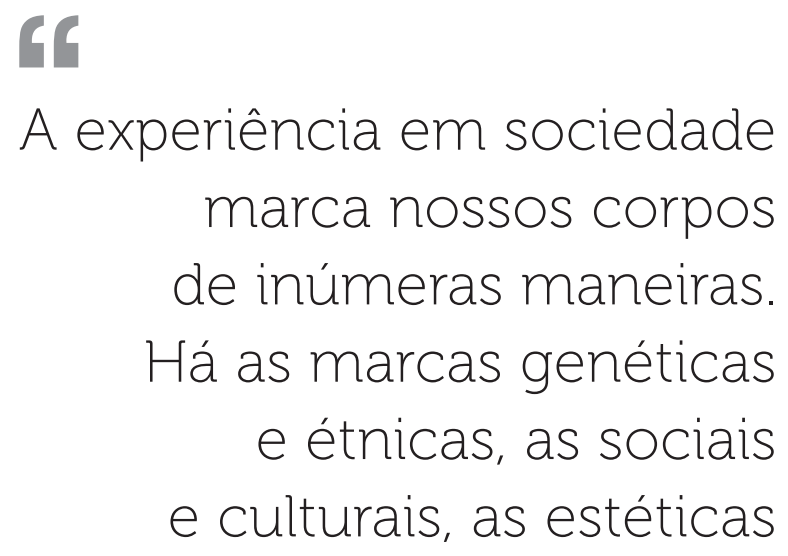
Rafaela Pacheco, médica de família e comunidade, sanitarista e professora do Curso de Medicina do Centro Acadêmico do Agreste, da UFPE, principia sua fala com uma citação da antropóloga Margaret Mead, segundo a qual o primeiro indício do que pode ser considerado civilização é um fêmur cicatrizado, uma vez que essa cicatrização só seria possível mediante o cuidado de um outro ser humano. Ou seja, ao invés de ser deixada para trás por ser uma presa fácil (como habitualmente ocorria em muitas culturas, sobretudo as nômades), essa pessoa foi cuidada (MEAD apud PACHECO, 2020).

Pacheco cita a fratura no campo da medicina que cindiu a hermenêutica da cura e dicotomizou a relação doente-cuidador, de um lado, e o método anátomo-clínico da biomedicina, de outro ver Contra a desumanização da medicina: crítica sociológica das práticas médicas modernas, de Paulo Henrique Martins (2003). Em seguida, ela associa a ideia dos corpos de risco ao que chama de "corpos nunca adequados", convidando-nos a pensar o cuidado numa perspectiva: de gênero, trazida pela teoria queer e pelo movimento LGBTQIA+; de raça, por meio do movimento negro, indígena, cigano e demais movimentos étnico-raciais; e de classe social, ressignificando o cuidado a partir dessas perspectivas. Pacheco completa seu raciocínio citando uma mesa de conversa com o neurocirurgião Sidarta Ribeiro e com o ambientalista Ailton Krenak, os quais defendem as perspectivas das cosmologias indígena e africana para romper com a lógica cartesiana da medicina ocidental (KRENAK; RIBEIRO, 2020).

Jayme Penerai (psicólogo e membro da Libertas) inicia o seu discurso citando o médico medieval Paracelso, segundo o qual "o médico é o medicamento de Deus" (PARACELso apud PENERAI, 2020), e homenageia as/os professoras/es do Curso de Medicina de Caruaru (Rodrigo Cariri, Verônica Oliveira, Eline Gomes e Rafaela Pacheco), dizendo que o ensino humanizado, no referido curso, seria a cura da fratura da conduta médica. Penerai reflete sobre as três primeiras letras da palavra solidariedade: sol, que aquece e abrange a todos, para falar de um pertencimento indistinto; como algo que deveria reger a medicina no momento atual. Convida-nos a refletir sobre nossas crenças e identificações, sobre quantas delas vieram dos nossos antepassados, mostrando que são as crenças recebidas sem autorreflexão as grandes responsáveis pelos preconceitos. Para romper com essa postura, é necessário que a sociedade busque uma ética do ser, e não do aparentar, ter ou consumir, e cita a "sociedade do cansaço", do coreano Byung-Chul 


\section{Como ficar dentro de casa} quando se vive em cômodos pequenos e insalubres? Como comprar álcool em gel quando não se tem dinheiro para comprar comida? Como ficar em casa quando se mora na rua?

Han (2015), segundo o qual a sociedade valoriza as pessoas que estão constantemente ocupadas, sem se importar com sua exaustão. Contextualizando o quanto de preconceito contra os chineses e os seus hábitos foi disseminado na pandemia, Penerai critica o presidente Jair Bolsonaro por desestimular o distanciamento social, e conclui afirmando que o cuidado humanizado e holístico é imprescindível ao pós-pandemia.

Grace Wanderley, Formadora Internacional em Análise Bionergética, psicoterapeuta e diretora da Libertas, fala que assim como o vírus é invisível a olho nu, as populações periféricas também são invisibilizadas e, por isso, seriam os corpos de "risco", destituídos das orientações preventivas e das condições para mantê-las. Como ficar dentro de casa quando se vive em cômodos pequenos e insalubres? Como comprar álcool em gel quando não se tem dinheiro para comprar comida? Como ficar em casa quando se mora na rua? Denunciando o que chama "sociedade da performance e desempenho", em que não há pausa para se ouvir a si mesmo, ao outro e à natureza, Wanderley ressalta a naturalização da violência (a ideia do "mata-mata" do futebol, os telejornais que defendem a morte dos infratores da lei etc.), concluindo que uma sociedade que não tem consciência sobre essa violência cotidiana é uma sociedade que não valoriza a vida. 
Ela cita os "memes" que falam em prender os idosos em gaiolas durante a pandemia como um grande desrespeito e uma violência contra essa população, evidenciando o afloramento de ações preconceituosas contra os chamados grupos de risco. Por fim, ela pondera que “corpos em risco são os de todos nós", mas o são, em especial, os das pessoas vulneráveis socialmente, que vivem nas ruas ou nas periferias e não têm orientações preventivas voltadas para a sua realidade; as que têm as imunidades mais fragilizadas devido à alimentação precária, aos fatores emocionais, e às condições socioambientais.

"Uma mulher gorda, de cabelos pretos e encaracolados [...]". Maria Clara Camarotti, arte-educadora, Especialista em Gestão Cultural e integrante do Coletivo Lugar Comum - Teatro, Dança e Performance, inicia se descrevendo. Como quem faz uma audiodescrição, ela parece nos convidar a vê-la de novo, ou, simplesmente, a vê-la de um modo mais atento. A isso se segue um convite para fechar os olhos, para respirar, e, depois, para percorrer nosso corpo com as mãos, provocando, talvez, uma outra forma de "ver", que acontece a partir do tato. Ela lança uma pergunta: "o olhar acompanha o toque ou é contrário a ele?" E complementa: “o corpo de vocês é uma doença?”. Camarotti se levanta e exibe o próprio corpo, enquanto afirma: “o meu corpo não é uma doença”. Ela narra o quanto já sofreu com taxações de pessoas que não sentem, mas classificam os corpos sem conhecê-los. Citando a poeta Alice Ruiz - "se lembra quando sentir era a forma mais sábia de saber e você não sabia?!" -, ela argumenta que a arte a ajuda a sentir e convida as/os profissionais de saúde a reaprenderem a sentir a si mesmos e ao próximo. Camarotti questiona, ainda, a relação direta entre obesidade e doença, reiterada pela sociedade atual e por profissionais de saúde, considerando que o cuidado, quando marcado por preconceitos e estigmas, machuca e mata. Várias pessoas se manifestam no chat, tecendo considerações e descrevendo o quanto a apresentação de Camarotti as marcou.

PANDEMIA, ARTE E SUBVERSÃO

Quais aspectos estão implicados na formação do humano, na construção do ser? Quais experiências, e como, vão nos construindo, e de que forma damos significado a elas ou as carregamos em hábitos, reações e padrões? Como a arte trabalha com isso, e por onde nos leva? Como ressignificar experiências com arte, transformar e transformar-se... Aspectos do inútil, da criação, da subversão e do ritual podem ser pistas para essa discussão, permeada pela 
complexidade de cada campo de trabalho na arte, na educação, e na mistura desses dois campos aplicada ao campo da saúde.

Professor de psiquiatria do NCv/UfPe, Mestre em Atenção Psicossocial pela UFRJ e doutorando em bioética pela UNB, Vinícius Vieira descreve alguns aspectos da crise e as ondas de preconceito que estão postas, defendendo que temos forças de manutenção e forças de subversão. Ele cita Rolando Toro, quando este afirma a criatividade como impulso de inovação frente à realidade, quebrando, assim, a ordem estabelecida, e propõe uma leitura de um trecho de $O$ lustre, de Clarice Lispector. No texto, a personagem Daniel propõe à sua irmã, Virgínia, a criação de uma sociedade das sombras.

[...] A Sociedade das Sombras sabe que você é vulgar porque você não pensa, como se diz, com profundeza, porque você só sabe seguir o que the ensinaram, está entendendo? A Sociedade das Sombras manda que você amanhã entre no porão, sente-se e pense muito, muito para saber o que é de você mesma e o que é que lhe ensinaram [...]" (LISPECTOR apud VIEIRA, 2020).

Líria Morays, professora de Artes Cênicas e do Mestrado Profartes, ambos da UFPB, e coordenadora da linha de pesquisa Radar 1 - Grupo de Improvisação em Dança, interpreta um texto a respeito de uma casa que "me olha, a casa me diz e me espera na cozinha, a varanda me grita que eu saia imediatamente e me mostra umas flores laranja”, e que é sucedido por uma performance na qual a vemos aparecer e desaparecer em diferentes ângulos e partes da casa (portas, banheiro, corredor). Ao fim da performance, ela conta que sua pesquisa em dança se relaciona à ocupação de lugares, considerando que um corpo que dança, se não estiver no lugar adequado para dançar, já é subversivo. Se subir num banco da praça, onde não é para subir - e, se for uma mulher preta, ainda pior. Citando André Lepecki (2011) e seus conceitos de "coreopolítica" e "coreopolícia" (que alude ao fato de a polícia conduzir os corpos por onde estes “podem" ou “não podem” ir), Morays pondera que a subversão se apresenta como uma ferramenta política. Citando artistas para pensar essa subversão do espaço e de perspectivas, ela finaliza dizendo que "é preciso viver a subversão e fazer existir um olhar para uma nova ordem" (MORAYs, 2020).

A fonoaudióloga, professora da Universidade Federal do Rio de Janeiro e coordenadora do Projeto de Extensão Laboratório de Sensibilidades e Devires (LSD) Mônica Rocha fala sobre sua atuação no projeto de um Laboratório de Sensibilidades e considera que "uma certa poeira da experiência do sensível pode fazer um 
deslocamento nos nossos modos de agir, pensar e sentir”. Ela cita a expressão "brincar de pensar", aludindo ao fato de a criança colocar em relação coisas que ainda não estão em relação, defendendo um pensamento em ato, e não a partir de decodificações prévias. Comenta o trabalho com crianças autistas, dizendo-se grata pela oportunidade de entregar-se com as crianças à produção discursiva de um corpo que não se coloca como decodificado. Rocha menciona a ideia de um corpo coletivo em estado "de aventura", questionando como será o enfrentamento da vida pós-pandemia, defendendo que "a primeira providência é esvaziar a minha mochila, os equipamentos que eu tinha", e ter a coragem de equipar o pensamento com outros dispositivos.

DESAFIOS DO SUS PARA O ENFRENTAMENTO DA PANDEMIA: DA POLÍTICA À PRODUÇÃO DO CUIDADO EM SAUUDE

A sétima live foi inteiramente pensada, produzida e realizada pelos estudantes extensionistas, e foi acrescentada ao projeto inicial a partir de uma reflexão sobre o seu crescimento e a participação dos mesmos ao longo do processo. Entendendo que o incentivo à autonomia é também uma ação desejada dentro de um projeto de extensão, a equipe acordou que essa ação iria encerrar essa fase do Sensíveis Perspectivas.

Ítalo Ricardo Santos Aleluia é professor da Universidade Federal do Oeste da Bahia e Doutor em Saúde Pública pelo Instituto de Saúde Coletiva da Universidade Federal da Bahia. Aleluia lembra que o sus é uma conquista constitucional da sociedade em favor do direito a uma saúde pública e coletiva, recordando que este atende, direta ou indiretamente, à toda população brasileira. Ele afirma que o sus: produz conhecimento através das pesquisas feitas pelas universidades federais e de diversos editais, forma profissionais (sendo um enorme campo de prática) e é, portanto, estratégico para um Estado inclusivo. Um dos maiores desafios do sus seria político, uma vez que, durante a gestão de Mandetta como ministro da saúde, por exemplo, vimos atores ligados a grupos privados levarem interesses próprios para o ministério, de forma que a racionalidade técnica fica submetida a interesses políticos. Um outro desafio seria de natureza econômica, se considerarmos toda a pressão de grupos econômicos para a flexibilização da quarentena, em detrimento de vidas humanas, sem mencionar as consequências adversas do teto de gastos e o desmonte das universidades federais. Tudo isso se desdobra no desafio de criar uma infraestrutura para o enfrentamento da crise, que envolveria a criação de 
leitos, a contratação de profissionais nas regiões mais remotas e a compra de equipamentos dentro de um contexto de desabastecimento a nível nacional, contexto agravado ainda pelo aumento da concorrência internacional para a compra de tais equipamentos.

A professora e coordenadora do curso de medicina da UFPE (Centro Acadêmico do Agreste) Carolina Paz, médica de família e comunidade, e Mestra em Promoção da Saúde, desenvolve sua fala a partir de uma reflexão sobre a necessidade de se voltar a questões básicas, que já foram escritas e testadas, mas que não foram colocadas em prática. Paz lembra que o sus, que vem trabalhando com os princípios de integralidade e de equidade por décadas, não tem podido colocá-los em prática na pandemia, por conta das políticas excludentes e genocidas do Governo Federal. Ela advoga que a ausência de uma política de participação social sólida dificulta o combate à pandemia neste momento excepcional. Paz cita o contact tracing, tido como uma novidade, e que seria o rastreamento de contatos já feitos com tuberculosos, mas que não está sendo colocado em prática. Ela finaliza afirmando que, diante de informações desconexas e da ausência de uma equipe de saúde que as represente, a população acaba por se sentir abandonada, o que deslegitima ainda mais o Ministério da Saúde e outras instituições como as universidades públicas.

A professora do Curso de Medicina da UfPe no Centro Acadêmico do Agreste Rosane Lacerda, Mestre e Doutora em Direito, Estado e Constituição pela Universidade de Brasília (UNB) e ex-assessora jurídica do Conselho Indigenista Missionário (Cimi), assume a palavra. Lacerda começa destacando o sus como fruto

\section{4}

Se o intensivista em saúde

se assemelha a um cavaleiro

medieval [...], como abrir os poros da medicina e da sociedade para nos sensibilizar com o 'nós'? 
de uma visão política, e também como espaço de disputa política. Ela destaca o movimento da Reforma Sanitária e a $8^{\text {a }}$ Conferência Nacional de Saúde (CNS) como marcos na construção do sus, os quais estão conectados à ruptura do Regime Militar e à elaboração da Constituinte. Prosseguindo nesse histórico, ela afirma que é a Constituinte, então, que define a saúde como direito e como parte de um sistema único. Na década de 1990, esse movimento ganha força com as Leis Orgânicas de Saúde (8.080/9o e 8.142/90), que estabelecem os mecanismos de participação da sociedade no controle social do sus. Ela ressalta a diferença entre o modelo proposto nas leis e sua prática, lembrando que o sus nunca recebeu um financiamento adequado ao desempenho de suas funções.

Continuando a elencar os desafios enfrentados pelo sus, Lacerda cita o imaginário que o associa a ideias de precariedade, reduzindo-o a uma lógica hospitalocêntrica, imaginário esse que seria reforçado pela mídia. Além disso, "o racismo institucional" e "a recente negação da política”, o negacionismo refletido nos baixos índices de isolamento social durante a pandemia, bem como a ausência de liderança política, são fatores que agravam ainda mais a situação da saúde pública no Brasil ${ }^{1}$.

\section{SENSÍVEIS PERSPECTIVAS, OU UMA CARTOGRAFIA DO CAOS}

A experiência com o projeto Sensíveis Perspectivas nos permitiu criar uma espécie de cartografia teórica, ética, estética e afetiva. O diálogo contínuo entre a equipe do LabSensi e as parceiras e os parceiros do Nucas/UPE, as colegas e os colegas de trabalho do NCV e as debatedoras e os debatedores provenientes de distintas áreas do saber, assim como as pessoas de lugares diversos do Brasil (São Paulo, Bahia, Rio de Janeiro, Recife, Caruaru, Gravatá) que se manifestaram por meio do chat, criou um mosaico de questões, de problematizações e de possíveis ações para o enfrentamento da crise sanitária deflagrada pela pandemia, mas a qual, entendemos, parece ter raízes em pensamentos e práticas muito anteriores à última mutação do vírus.

A cartografia é composta por muitos riscos, por muitas tramas. Ainda uma cartografia do caos, mas com vislumbres de alguns caminhos. Entre esses, a necessidade de colocar no mapa do cuidado aquelas “existências mínimas”, ampliando o direito à saúde aos "povos não aldeados” (parafraseando Vânia Fialho), deslindando

1 Problemas no sinal da rede tornaram alguns trechos da fala de Lacerda inaudíveis. Sintetizamos, aqui, as partes que ficaram inteligíveis. 
as ideologias do vírus (Artur Perrusi), e buscando uma civilidade capaz de parar para cicatrizar um metafórico fêmur partido (Rafaela Pacheco, que cita Margaret Mead).

Se o intensivista em saúde se assemelha a um cavaleiro medieval (na tentativa de blindar a contaminação, como relatou o médico Pedro Diniz), como abrir os poros da medicina e da sociedade para nos sensibilizar com o "nós"? Como combater um imaginário que associa o sus à precariedade (Rosane Lacerda) e, a partir desse imaginário estigmatizante, abandona as conquistas de uma luta que levou décadas para implantar um dos maiores e mais complexos sistemas de saúde pública do mundo? Tornar o sus um “corpo duelável”, ou seja, um corpo pelo qual se vale a pena lutar (segundo Judith Butler, citada por Diogivânia Maria), o corpo do "nós", significaria também colocar no mapa da existência os indígenas, os corpos desviantes, os "preconceituados" (Jayme Penerai)?

Ainda não temos vacina. Nem solução biomédica, nem solução ética-estética para uma problemática tão imensa. Mas o que ecoa nessas múltiplas vozes que gritam nessa cartografia do caos é o grito desse "coletivo em aventura" (ROCHA, 2020), que clama pela necessidade de um olhar sistêmico e sensível da saúde sobre o corpo do "nós". A economia não pode ou não devia se opor à vida; e corpos de risco, como disse Grace Wanderley, somos todos nós.

\section{REFERÊNCIAS}

ALELUIA, Ítalo Ricardo Santos. Desafios do SUS para o enfrentamento da pandemia: da política à produção do cuidado em saúde. In: Sensíveis Perspectivas. Youtube, canal do Núcleo de Cartografias da Subjetividade Nucas, 15 jun. 2020. Disponível em: https://www.youtube.com/watch?v=aooiUSIJP2O\&t=31s. Acesso em: 31 jul. 2020.

ALMEIDA, Alfredo Wagner Berno de. A ideologia da decadência: leitura antropológica a uma história da agricultura do Maranhão. Rio de Janeiro: Editora Casa 8/ Fundação Universidade do Amazonas, 2008. BUTLER, Judith. Sin miedo: formas de resistencia a la violencia de hoy. Barcelona: Penguin Random House Grupo Editorial España, 2020. E-book.

CAMAROTTI, Maria Clara. Corpos em risco, por uma ética do cuidado. In: Sensíveis Perspectivas. Youtube, canal do Núcleo de Cartografias da Subjetividade - Nucas, 1 jun. 2020. Disponível em: https://www. youtube. $. \mathrm{com} /$ watch? $\mathrm{v}=55 \mathrm{eyAG} 3 \mathrm{Snn}$ \& $\mathrm{-}$ $\mathrm{t}=3717 \mathrm{~s}$. Acesso em: 31 jul. 2020.

CUSICANQUI, Silvia Rivera. Ch'ixinakax utxiwa: A reflection on the practices and discourses of decolonization. South Atlantic Quarterly, Durhan, v. 111, n. 1, p. 95-109, 2012.

DA SILVA, Diogivânia. Entre o medo e a morte: sensações em meio a pandemia. In: Sensíveis Perspectivas. Youtube, canal do Núcleo de Cartografias da Subjetividade Nucas, 18 maio 2020. Disponível em: https:// www.youtube.com/watch?v=JDVjDqKoI$\mathrm{U} \& \mathrm{t}=17 \mathrm{~s}$. Acesso em: 31 jul. 2020.

DE ANIS, Ana. Tramas performáticas como modos de existência. In: Sensíveis Perspectivas. Youtube, canal do Núcleo de Cartografias da Subjetividade - Nucas, 25 maio de 2020. Disponível em: https://www. youtube.com/watch?v=tLF2b_boAkM.

Acesso em: 31 jul. 2020.

DE CARLI, Caetano. A sociologia do vírus, ou quando o biológico é social. In: Sensíveis 
Perspectivas. Youtube, canal do Núcleo de Cartografias da Subjetividade - Nucas, 11 maio 2020. Disponível em: https://www.youtube.com/watch? $\mathrm{v}=$ PmUWogT_SYo\&t= 2132s. Acesso em: 31 jul. 2020.

DINIZ, Pedro Carvalho. Entre o medo e a morte: sensações em meio a pandemia. In: Sensíveis Perspectivas. Youtube, canal do Núcleo de Cartografias da Subjetividade Nucas, 18 maio 2020. Disponível em: https:// www.youtube.com/watch?v=JDVjDqKoI$\mathrm{U} \& \mathrm{t}=17 \mathrm{~s}$. Acesso em: 31 jul. 2020.

FEITOSA, Saulo Ferreira. As existências mínimas: por uma ética da pluralidade na saúde. In: Sensíveis Perspectivas. Youtube, canal do Núcleo de Cartografias da Subjetividade Nucas, 4 maio 2020. Disponível em: https:// www.youtube.com/watch?v=J1Kh2oq2W $c \& t=10 s$. Acesso em 31 jul. 2020.

FIALHO, Vânia. A sociologia do vírus, ou quando o biológico é social. In: Sensíveis Perspectivas. Youtube, canal do Núcleo de Cartografias da Subjetividade - Nucas, 11 maio 2020. Disponível em: https://www. youtube.com/watch?v=PmUWogT SYo\&t=2132s. Acesso em: 31 jul. 2020.

GERMANY, Heloísa. Tramas performáticas como modos de existência. In: Sensíveis Perspectivas. Youtube, canal do Núcleo de Cartografias da Subjetividade - Nucas, 25 maio 2020. Disponível em: https://www. youtube.com/watch?v=tLF2b_boAkM.

Acesso em: 31 jul. 2020.

HAN, Byung-Chul. Sociedade do cansaço. Petrópolis: Vozes Limitada, 2015.

KRENAK, Ailton. Ideias para adiar o fim do mundo. São Paulo: Companhia das Letras, 2019.

KRENAK, Ailton; RIBEIRO, Sidarta. Sonhos para adiar o fim do mundo. In: Na Janela Festival. Youtube, canal da Companhia das Letras, 24 maio 2020. Disponível em: https:// www.youtube.com/watch?v=95tOtpk4Bnw. Acesso em: 31 jul. 2020.

LACERDA, Rosane. Desafios do SUS para o enfrentamento da pandemia: da política à produção do cuidado em saúde. In: Sensíveis Perspectivas. Youtube, canal do Núcleo de Cartografias da Subjetividade - Nucas, 15 jun. 2020. Disponível em: https://www.youtube.com/watch? $\mathrm{v}=$ aooiUSIJP2o $\& \mathrm{t}=31 \mathrm{~s}$. Acesso em: 31 jul. 2020.

LAPOUJADE, David. As existências mínimas. São Paulo: N-1 Edições, 2017.
LEPECKI, André. Coreopolítica e coreopolícia. Revista de Antropologia, Florianópolis, v. 13, n. 1, p. 41-60, 2011.

LATOUR, Bruno. Ciência em ação: como seguir cientistas e engenheiros sociedade afora. São Paulo: Unesp, 2000.

LIMA, Nísia Trindade; BUSS, Paulo Marchiori; PAES-SOUSA, Rômulo. A pandemia de Covid-19: uma crise sanitária e humanitária. Cadernos de Saúde Pública, Rio de Janeiro, v. 36, n. 7, p. 1-4, 2020.

LUDERS, Saulo. As existências mínimas: por uma ética da pluralidade na saúde. In: Sensíveis Perspectivas. Youtube, canal do Núcleo de Cartografias da Subjetividade Nucas, 4 maio 2020. Disponível em: https:// www.youtube.com/watch?v=J1Kh2oq2W_ $c \& \mathrm{t}=10$ s. Acesso em 31 jul. 2020.

MALTA, Deborah Carvalho et al. A pandemia da Covid-19 e as mudanças no estilo de vida dos brasileiros adultos: um estudo transversal, 2020. Epidemiologia e Serviços de Saúde, Brasília, v. 29, n. 4, p. 1-13, 2020.

MARTINS, Paulo Henrique. Contra a desumanização da medicina: crítica sociológica das práticas médicas modernas. Petrópolis: Vozes, 2003.

MBEMBE, Achille. Necropolítica. São Paulo: N-1 Edições, 2018.

MBEMBE, Achille. Crítica da razão negra. São Paulo: N-1 Edições, 2018a.

MBEMBE, Achille. O direito universal à respiração. Disponível em: http://www.ihu. unisinos.br/78-noticias/598111-o-direito-universal-a-respiracao-artigode-achille-mbembe. Acesso em: 15 out. 2020.

MORAYS, Líria. Pandemia, arte, subversão. In: Sensíveis Perspectivas. Youtube, canal do Núcleo de Cartografias da Subjetividade Nucas, 8 jun. 2020. Disponível em: https:// www.youtube.com/watch?v=kyhUMaAiYFc. Acesso em 31 jul. 2020.

ODÉCIO, Antônio. Tramas performáticas como modos de existência. In: Sensíveis Perspectivas. Youtube, canal do Núcleo de Cartografias da Subjetividade - Nucas, 25 maio 2020. Disponível em: https://www. youtube.com/watch? $\mathrm{v}=\mathrm{tLF} 2 \mathrm{~b} \_$boAkM. Acesso em: 31 jul. 2020.

PACHECO, Rafaela Alves. Corpos em risco, por uma ética do cuidado. In: Sensíveis Perspectivas. Youtube, canal do Núcleo de Cartografias da Subjetividade - Nucas, o1 jun. 2020. Disponível em: https://www. 
youtube.com/watch?v=55eyAG 3 Snns \&$\mathrm{t}=3717 \mathrm{~s}$. Acesso em: 31 jul. 2020 .

PAZ, Carolina. Desafios do SUS para o enfrentamento da pandemia: da política à produção do cuidado em saúde. In: Sensíveis Perspectivas. Youtube, canal do Núcleo de Cartografias da Subjetividade - Nucas, 15 jun. 2020. Disponível em: https://www. youtube.com/watch? $\mathrm{v}=$ aooiUSIJP20\&t=31s. Acesso em: 31 jul. 2020.

PENERAI, Jayme. Corpos em risco, por uma ética do cuidado. In: Sensíveis Perspectivas. Youtube, canal do Núcleo de Cartografias da Subjetividade - Nucas, 1 jun. 2020. Disponível em: https://www.youtube. com $/$ watch $? \mathrm{v}=55 \mathrm{eyAG} 3 \mathrm{Snns} \& \mathrm{t}=3717 \mathrm{~s}$. Acesso em: 31 jul. 2020.

SANTOS, Boaventura de Sousa. Para além do pensamento abissal: das linhas globais a uma ecologia de saberes. Revista crítica de ciências sociais, Coimbra, n. 78, p. 3-46, 2007.

PERRUSI, Artur. A sociologia do vírus, ou quando o biológico é social. In: Sensíveis Perspectivas. Youtube, canal do Núcleo de Cartografias da Subjetividade - Nucas, 11 maio 2020. Disponível em: https://www. youtube.com/watch?v=PmUWogT_SYo\&t =2132s. Acesso em: 31 jul. 2020 .

ROCHA, Mônica. Pandemia, arte, subversão. In: Sensiveis Perspectivas. Youtube, canal do Núcleo de Cartografias da Subjetividade - Nucas, 8 jun. 2020. Disponível em: https://www.youtube.com/watch?$\mathrm{v}=$ kyhUMaAiYFc. Acesso em: 31 jul. 2020.

SEIJAS, Nirlyn. Entre o medo e a morte: sensações em meio à pandemia. In: Sensíveis Perspectivas. Youtube, canal do Núcleo de Cartografias da Subjetividade - Nucas, 18 maio 2020. Disponível em: https://www. youtube.com/watch? $\mathrm{v}=J \mathrm{DVjDqKoI}=-\mathrm{U} \& \mathrm{t}-$ 17s. Acesso em: 31 jul. 2020.

SPENCER, Maria Eduarda. As existências mínimas: por uma ética da pluralidade na saúde. In: Sensíveis Perspectivas. Youtube, canal do Núcleo de Cartografias da Subjetividade - Nucas, 4 maio 2020. Disponível em: https://www.youtube.com/ watch?v=J1Kh2oq2W_c\&t=10s. Acesso em 31 jul. 2020.

VIEIRA, Vinícius. Pandemia, arte, subversão. In: Sensíveis Perspectivas. Youtube, canal do Núcleo de Cartografias da Subjetividade Nucas, 8 jun. 2020. Disponível em: https:// www.youtube.com/watch? $\mathrm{v}=\mathrm{kyhUMaAiY}$ Fc. Acesso em: 31 jul. 2020.

WANDERLEY, Grace. Corpos em risco, por uma ética do cuidado. In: Sensíveis Perspectivas. Youtube, canal do Núcleo de Cartografias da Subjetividade - Nucas, 1 jun. 2020. Disponível em: https://www. youtube.com/watch? $\mathrm{v}=55 \mathrm{eyAG} 3 \mathrm{Snn}$ \& $\mathrm{-}$ $\mathrm{t}=3717$ s. Acesso em: 31 jul. 2020.

Texto submetido em: 31 jul. 2020. Aprovado em: 16 out. 2020.

COSTA, Anamaria Sobral; ARAÚJO, Eline Gomes de; SILVA, Taciano Valério Alves da; SILVA, Andrew Pereira da; SILVA, Karlla Stephanie; SOUZA, Pedro Érico de. Entre lives e pandemia: um relato de percurso do projeto Sensíveis Perspectivas. Estudos Universitários: revista de cultura, Recife, v. 37, n. 1/2, p. 192-214, dez. 2020. ISSN Edição Digital: 2675-7354. 